\title{
Habitus políticos en la región de Antofagasta. Una propuesta metodológica
}

\section{Luis Miguel Rodrigo}

Universidad Católica del Norte. Departamento de Economía

lrodrigo@ucn.cl

\section{Resumen}

Este trabajo estudia la estructuración de la subjetividad política en la región de Antofagasta, situada en el norte de Chile, en un contexto socioeconómico prototípicamente neoliberal. A partir de una muestra de treinta relatos de vida sometidos a un análisis sociológico del discurso, se construye un conjunto de tipologías que son denominadas habitus políticos. En el análisis, se identifican cuatro experiencias vitales fundamentales en la estructuración de estos habitus políticos: el posicionamiento familiar en el conflicto histórico (golpe de Estado y dictadura miliar), la clase social, la trayectoria social y la trayectoria espacial. Se concluye que la relación con el orden social es prediscursiva, por lo que resulta necesario sumar el análisis biográfico de las disposiciones políticas (estructuras individuales de subjetividad política) al análisis de los discursos políticos (estructuras sociales de subjetividad política).

Pablas clave: Bourdieu; sociología política; neoliberalismo; análisis sociológico del discurso; relatos de vida

\section{Abstract. Political habitus in the Antofagasta region: A methodological proposal}

This paper studies the structuring of political subjectivity in the Antofagasta Region of northern Chile in a prototypically neoliberal socioeconomic context. Using a sample of thirty life stories and by means of sociological discourse analysis, we construct a set of types called political habitus. The analysis identifies four fundamental life experiences that structure these political habitus: the relative positioning in the historical conflict (coup and military dictatorship), the social class, the social trajectory and the spatial trajectory. We conclude that the relationship with the social order is pre-discursive. Hence, it is necessary to add the biographical analysis of political provisions (individual structures of political subjectivity) to the analysis of political discourse (social structures of political subjectivity).

Keywords: Bourdieu; political sociology; neoliberalism; sociological discourse analysis; life stories 


\begin{aligned} & \multicolumn{2}{c}{ Sumario } \\ & Introducción Experiencia de vida II. La clase social \\ & Habitus, dominación simbólica y Experiencia de vida III. La trayectoria \\ & posición social social \\ & El caso chileno Experiencia de vida IV. La trayectoria \\ & Metodología espacial \\ & Región de Antofagasta Estructura del habitus político \\ & Análisis Conclusiones \\ & Experiencia de vida I. El posicionamiento Referencias bibliográficas \end{aligned}

familiar en el conflicto histórico

\section{Introducción}

El problema de la dominación social ha sido sistemáticamente ignorado por la racionalidad dominante, por resultar imposible en un contexto de democracia formal y libertad económica individual. En este sentido, hay que señalar que el tipo de racionalidad que propone el neoliberalismo de Hayek y Friedman, fundamentado en la teoría económica neoclásica, no concibe que los individuos puedan tomar decisiones contrarias a su propio interés, a menos que no dispongan del tiempo ni de la información necesarios (modelo de la racionalidad limitada). Por lo anterior, la supuesta adaptación del pueblo chileno al orden social neoliberal en un contexto de democracia formal es frecuentemente interpretada (y utilizada) por los defensores del neoliberalismo como una prueba de la validez social de esta doctrina o, al menos, de su posibilidad de coexistencia con un régimen democrático.

Tanto la teoría social clásica como la contemporánea han propuesto distintas respuestas al problema de la dominación. Posteriormente, analizaremos algunas de estas propuestas teóricas. En nuestro caso, vamos a abordar el problema de la adaptación al orden social neoliberal en Chile utilizando algunas de las herramientas teórico-metodológicas que nos ofrece Pierre Bourdieu. Concretamente, el objetivo de este artículo es reconstruir las estructuras individuales de subjetividad política, los habitus políticos que utilizan los chilenos para relacionarse con el orden social neoliberal.

\section{Habitus, dominación simbólica y posición social}

El problema de la dominación social ha sido abordado por diversos autores (Marx, 2001 y 2005; Marx y Engels, 1994; Freud, 1997; Fromm, 1973; Marcuse, 1993; Althusser, 1974; Laclau, 1987 y 2000; Žižek, 2004 y 2010; Festinger, 1975; Jost y Banaji, 1994), cuyos planteamientos pueden agruparse en dos grandes perspectivas explicativas: la explicación interna y la explicación externa (Rodrigo, 2013).

La explicación interna está planteada en la teoría de la alienación de Marx, los mecanismos de defensa de Freud, los mecanismos de evasión de Fromm, la 
búsqueda de la plenitud lacaniana, la disonancia cognitiva de Festinger y la justificación del sistema de Jost y Banaji. Esta explicación hace referencia a la capacidad y a la necesidad que tienen los sujetos de adaptarse al orden social en que están insertos. Desde esta perspectiva, no es necesaria la agencia de ningún actor social externo (como las clases dominantes o el modo de producción capitalista) para mantener el orden social, ya que su reproducción estaría garantizada por propiedades consustanciales a los sujetos.

La explicación externa, por su parte, está planteada en la teoría del interés de Marx, la sociedad de consumo de Marcuse y los aparatos ideológicos del Estado (AIE) de Althusser. Para esta perspectiva, la reproducción del orden social se explica por el trabajo continuo de un determinado agente social (ya sean las clases dominantes o el modo de producción capitalista), que, gracias a su poder (de origen económico), consigue imponer sus intereses (económicos) al resto de la sociedad.

El enfoque interno es muy pesimista respecto a la posibilidad de cambio social (como superación de un orden social injusto), pues nos presenta una sociedad sin conflicto que se reproduce automáticamente por las propiedades de los sujetos. El enfoque externo, sin embargo, nos presenta una sociedad en conflicto en la que los dominados, potencialmente, podrían apropiarse de los medios de dominación (medios de producción o AIE) y utilizarlos para imponer un nuevo orden social.

En este sentido, consideramos que la obra de Bourdieu aporta elementos teóricos que permiten integrar y comprender ambos enfoques, disolviendo su aparente oposición. Aquí nos centraremos en su teoría del habitus, de la dominación simbólica y de la posición social, ya que estos procesos atraviesan la totalidad del universo social.

Para Bourdieu, las estructuras mentales con las que operan los agentes son el producto de la encarnación de las estructuras sociales en las que han estado inmersos. Así, el habitus es un sistema de disposiciones de percepción y valoración que orienta a los agentes en el mundo social (Bourdieu, 2001: 26). En este sentido, el habitus será un determinado tipo de subjetividad producido por unas condiciones de existencia determinadas (Bourdieu, 1991: 92).

Como «estructura estructurada», el habitus es un producto social, no ha sido adquirido de forma biológica, su génesis es sociohistórica. Como «estructura estructurante», el habitus es un productor social, pues orienta y posibilita una práctica social prerreflexiva o «natural».

Bourdieu entiende el mundo social como un mundo doblemente objetivado o estructurado. La "objetividad del primer orden» hace referencia a las estructuras sociales objetivas, constituidas por la distribución desigual de los recursos socialmente valorados (los distintos tipos de capital), que, como sistemas de relaciones entre posiciones, funcionan de forma independiente a la conciencia de los agentes que actúan en ellos. Por otro lado, la «objetividad del segundo orden» se refiere a las estructuras mentales constituidas por los esquemas simbólicos de clasificación y valoración, que orientan y dan sentido a las prácticas sociales de los agentes. 
Este «segundo orden» es el resultado de la transformación simbólica del primero, es decir, que las estructuras mentales (los habitus) tienen su origen y se corresponden con las estructuras sociales objetivas, los sistemas de clasificaciones están determinados socialmente (Bourdieu y Wacquant, 2005). Esta correspondencia entre las estructuras sociales objetivas y las estructuras mentales es la que posibilita que el mundo social sea percibido como «natural» por los agentes sociales (Bourdieu y Wacquant, 2005: 166).

Las consecuencias políticas del proceso son evidentes, al ser las estructuras mentales los únicos instrumentos de percepción y apreciación de los agentes, son, necesariamente, los instrumentos para su dominación. La dominación social, por tanto, es fundamentalmente dominación simbólica, conseguida mediante la incorporación (en lo biológico) de todas las divisiones y relaciones sociales objetivas.

Dicha incorporación se lleva a cabo ejerciendo sobre el cuerpo una violencia simbólica, esto es, la imposición de un conjunto de esquemas de conocimiento y valoración del mundo social que ocultan su arbitrariedad cultural a quien lo adquiere. De esta manera, para los dominados, el mero acto de conocimiento de la realidad social supone un reconocimiento de la dominación. Así, la violencia simbólica convierte a los dominados en agentes activos y necesarios para su dominación. Podemos decir, entonces, que la dominación simbólica se presenta cuando los esquemas mentales de los dominados (Bourdieu, 2003b: 50) se suman a la imposición o demanda de los dominadores.

La imposición de los mismos esquemas de conocimiento a todos los agentes sociales es lo que permite la experiencia dóxica o (re)conocimiento del mundo social desde el sentido común, un conjunto de verdades autoevidentes que no requieren ser discutidas y que permiten un entendimiento automático. Para Bourdieu, es la doxa (incorporada mediante la violencia simbólica) la que permite el ajuste prerreflexivo («formas de pensar que no son pensadas») entre los agentes y las estructuras sociales objetivas. Por tanto, en la teoría bourdieuniana, la dominación social es prediscursiva y preconsciente, no requiere de construcciones ideológicas ni del trabajo de persuasión o engaño de los dominantes, sino que es el resultado del mero acto de percepción y conocimiento por parte de los dominados (Bourdieu, 1988: 21).

Por otro lado, para entender las posiciones politicas de los agentes, al igual que otras prácticas sociales, debemos tener en cuenta la posición que estos ocupan en el espacio social y la inculcación (socialización) político-religiosa ${ }^{1}$ desde la infancia. Hay que recordar que Bourdieu construye el espacio social fundamentalmente a partir de tres dimensiones ${ }^{2}$ : el volumen del capital, la estructura del capital y la evolución en el tiempo de estas dos propiedades (la trayectoria). Se trata, así, de agrupar a los agentes más homogéneos posibles desde el punto de vista de la producción de los habitus y de las prácticas (ver el mapa topológico 1).

1. Para Bourdieu, la socialización religiosa es una forma eufemistizada de la socialización política.

2. Aunque no excluye el resto de propiedades sociales relevantes (género, edad, posición geográfica, etc.). 
Mapa topológico 1. Espacio de las posiciones sociales

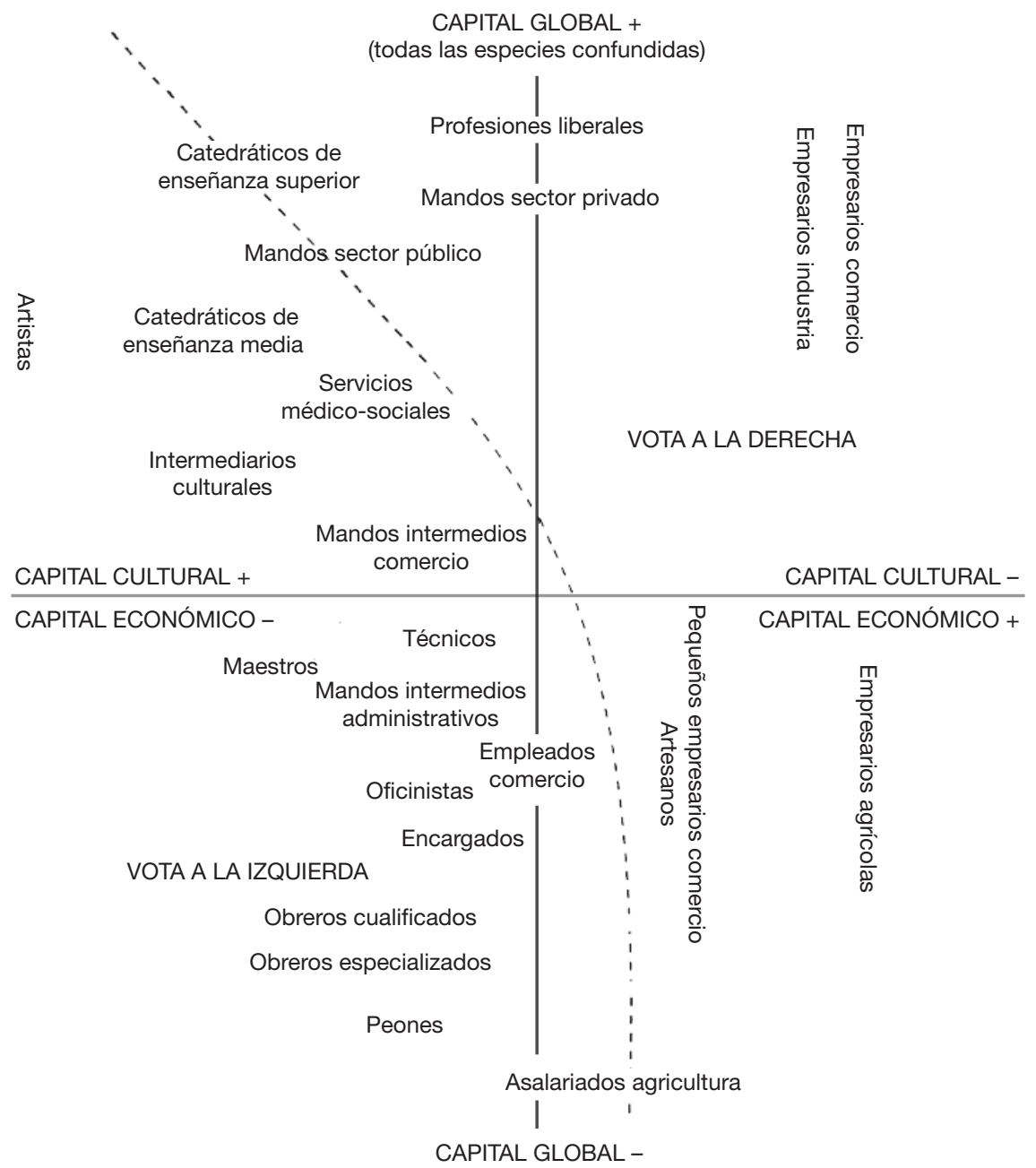

Nota: del original, se han suprimido los estilos de vida. Las líneas punteadas indican el límite entre la orientación probable hacia la derecha o hacia la izquierda.

Fuente: Bourdieu, 2002: 17.

\section{El caso chileno}

La violencia extrema del golpe de Estado de 1973 marca el principio de un periodo en la historia de Chile durante el que se utilizó de manera sistemática el terrorismo de Estado (secuestros, torturas, asesinatos y desapariciones) para reprimir a la población (Informe Rettig, 1991; Informe Valech, 2004). El padecimiento que sufrieron los chilenos en aquella situación límite tuvo 
importantes consecuencias que todavía perduran en las relaciones sociales, la cultura política y la subjetividad.

La «radiografía» cultural que nos presenta sobre Chile la Encuesta Mundial de Valores y el Latinobarómetro, nos describe un país que se caracteriza por una desconfianza social altísima y creciente, solo Brasil presenta un nivel inferior a Chile en "confianza interpersonal» (Latinobarómetro, 2009). Este rasgo ha sido identificado en otras latitudes como típicamente neoliberal (Rodríguez, 2003).

La evitación del conflicto, especialmente del político, y la búsqueda continua del consenso es otro rasgo característico de las relaciones entre chilenos. El miedo al enfrentamiento produce la evitación de temas potencialmente conflictivos, es decir, se evita la autodefinición política. La sobrevaloración del consenso y la norma en las relaciones sociales (el formalismo y el legalismo) son las consecuencias del miedo a la confrontación (Lira y Castillo, 1993; Lagos, 2007).

Por otro lado, el autoritarismo, el clasismo, el racismo y el machismo se mantienen con fuerza en esta sociedad, si bien es cierto que estas actitudes están fuertemente determinadas por la clase social, siendo menos acusadas en las clases acomodadas (Canales, 2007).

Respecto a la cultura política, hay que decir que las actitudes democráticas están poco instaladas entre los chilenos. Chile es el país latinoamericano donde peor se valoran las acciones políticas directas (manifestaciones, huelgas, etc.) llevadas a cabo por la ciudadanía. Además, el fatalismo político está muy presente. Es el país latinoamericano donde más gente piensa que es imposible cambiar la sociedad mediante la acción política (Latinobarómetro, 2008).

Por último, habría que señalar el monopolio ideológico neoliberal que caracteriza al campo mediático chileno, diseñado durante la dictadura pinochetista (1973-1990) y que se ha mantenido vigente hasta la actualidad (Rodrigo, 2013; Arriagada et al., 2010). Entendemos que estos rasgos de la subjetividad política chilena no pueden explicarse fuera del marco sociohistórico de la revolución neoliberal que desarrolló la dictadura pinochetista (Mayol, 2012; Moulian, 2002; Salazar y Pinto, 1999).

\section{Metodología}

Para reconstruir la «objetividad del segundo orden» en Chile, esto es, las estructuras subjetivas individuales ${ }^{3}$ o habitus, se utilizó la estrategia metodológica del relato de vida y del análisis sociológico del discurso en la forma en que este ha sido teorizado y puesto en práctica por la Escuela Cualitativista de Madrid (Ibáñez, 1979; Ortí, 1989; Alonso, 1998; Conde, 2009; Colectivo IOÉ, 2010).

3. Para la reconstrucción de las estructuras sociales objetivas de Chile (campo económico, político, mediático y estructura social), así como de las estructuras sociales de subjetividad (discursos políticos), ver Rodrigo (2013). 


\section{Relato de vida}

Se utilizó una adaptación de esta técnica para poder abordar la presente investigación (Pujadas, 1992). Su objetivo es generar la información necesaria para poder (re)construir los habitus de los entrevistados. El relato de vida tiene como hilo conductor la biografía del entrevistado, desde su niñez hasta el presente. Sin embargo, frente a su uso típico, nuestro objetivo no fue construir una narración singular que rescate la interpretación y el sentido que el entrevistado da a su vida (objetivo fenomenológico) ${ }^{4}$, sino que se pretendía:

a) Reconstruir las distintas condiciones de existencia objetivas que estructuraron el habitus del entrevistado durante su trayectoria vital.

b) Conocer sus esquemas políticos de percepción y valoración.

c) Conocer los discursos políticos que (re)producen los entrevistados.

La técnica estuvo estructurada en dos momentos diferentes: un primer momento objetivo-descriptivo y un segundo momento subjetivo-político.

En un primer momento, el relato se centró en la reconstrucción de las condiciones de existencia, esto es, en los diferentes recursos sociales y familiares (volumen y tipos de capital), así como la posición en las distintas relaciones de dominación, especialmente de género, clase y campo social, que han acompañado al entrevistado a lo largo de su vida. En ese momento, el entrevistado se convirtió en un testigo de las estructuras sociales objetivas bajo las que se desarrolló su vida, por tanto, la dimensión descriptivo-objetiva de lo dicho (función referencial) fue la más relevante.

En un segundo momento, se trató de reconstruir los esquemas políticos de percepción y valoración, así como los discursos políticos que (re)produce el entrevistado, es decir, las estructuras subjetivas individuales y sociales en las que participa. Nos centramos, por tanto, en hacer emerger las dimensiones del saber (la doxa) y del deber ser (lo normativo-valórico), por lo que el entrevistado se transformó en opinantes.

\section{El habitus político}

Pese a su gran difusión y prestigio en la teoría social, el habitus bourdieuniano se encuentra aún en una etapa emergente como instrumento metodológico, pues los trabajos empíricos que lo han utilizado son todavía escasos (Sánchez, 2008; Bourgois y Schonberg, 2008; Connolly et al., 2009; Ferreira y Ferrante, 2010; Wacquant, 2011; García, 2011) ${ }^{6}$. Por lo anterior, su instrumentaliza-

4. Junto con Bourdieu, no creemos que una «vida» constituya un todo o un conjunto coherente que pueda ser aprehendido y dotado de un «propósito» subjetivo o sentido (Bourdieu, 2002: 74-83).

5. Esta diferencia en los roles que pueden adoptar los entrevistados (testigos vs. opinantes) se encuentra desarrollada en Canales (2006: 265-287).

6. Los trabajos citados solo pretenden ejemplificar esta línea de investigación, no hacer una descripción exhaustiva. 
ción supone aceptar un cierto grado de incertidumbre. En cualquier caso, el presente trabajo también se propone contribuir a hacer operativo el concepto para el trabajo empírico.

En el marco teórico, hemos ofrecido una breve descripción del concepto de habitus en la teoría de Bourdieu. A continuación, se presentará una definición operativa que explica la forma concreta en la que este concepto ha sido utilizado en nuestro análisis:

a) Los habitus son construcciones teóricas, en forma de tipologías, que realiza el investigador a partir del análisis de un conjunto determinado de casos empíricos. Son, por tanto, tipos ideales (Weber, 2008) que pretenden destacar las características comunes de distintos casos reales, por lo que resultaría difícil encontrar un habitus puro en la realidad.

b) Los habitus contienen dos dimensiones relacionadas; una subjetiva y otra objetiva que la determina. La dimensión subjetiva del habitus consiste en un conjunto de disposiciones de percepción y valoración que orientan las prácticas sociales de los agentes. Por otro lado, la dimensión objetiva del habitus está compuesta por un conjunto de experiencias o situaciones sociales que han sufrido los agentes a lo largo de sus trayectorias vitales y que han estructurado sus disposiciones subjetivas. Esquematizando, los habitus son unas formas de ser generadas por unas formas de vida.

c) Por habitus politico nos referimos, concretamente, a las disposiciones subjetivas que los agentes utilizan para relacionarse, ya sea de forma crítica, adaptativa o regresiva, con el orden social y al conjunto de experiencias objetivas que las han generado.

Entendemos que esta estrategia metodológica minimiza el riesgo apuntado por Criado (2013) de realizar una falsa atribución causal, ya sea por desconocer la trayectoria social de los agentes, suponiéndoles unas experiencias vitales que nunca tuvieron o por no considerar suficientemente su posición social actual. Por otro lado, hay que señalar que también existe el riesgo contrario, el de atribuir el comportamiento de los agentes a una racionalidad «natural» (utilitarista) que estaría determinada y autoexplicada por su eficiencia, desconociendo el proceso social de incorporación de dicha racionalidad. En cualquier caso, consideramos que solo un estudio longitudinal cualitativo ${ }^{7}$ podría reducir al máximo, que no evitar, la imputación de relaciones causales falsas.

\section{Población de estudio y muestra}

La población de estudio son los chilenos mayores de treinta años que trabajan en la región de Antofagasta. La decisión de no contemplar a personas menores de dicha edad se debe a que consideramos que las estructuras de subjetividad

7. El alto costo de este tipo de estudio, que debería extenderse durante décadas, lo deja fuera de nuestro alcance. 
Cuadro 1. Diseño muestral

\begin{tabular}{|c|c|c|c|}
\hline Clase/campo & Campo universitario & Campo minero & N. ${ }^{\circ}$ de casos para cada clase \\
\hline $\begin{array}{l}\text { Clase superior } \\
\text { (k. económico): }\end{array}$ & No corresponde & $\begin{array}{l}\text { Empresario, } 51 \\
\text { Empresaria, } 49\end{array}$ & $\begin{array}{l}2 \text { casos } \\
\text { Hombres: } 1 \\
\text { Mujeres: } 1\end{array}$ \\
\hline $\begin{array}{l}\text { Clase superior } \\
\text { (k. cultural): }\end{array}$ & $\begin{array}{l}\text { Profesor, } 79 \\
\text { Profesor, } 32 \\
\text { Profesora, } 68\end{array}$ & $\begin{array}{l}\text { Traductor, } 32 \\
\text { Traductor, } 29 \\
\text { Ingeniero, } 28\end{array}$ & $\begin{array}{l}6 \text { casos } \\
\text { Hombres: } 5 \\
\text { Mujeres: } 1\end{array}$ \\
\hline $\begin{array}{l}\text { Clases medias } \\
\text { (k. cultural): }\end{array}$ & $\begin{array}{l}\text { Administrativo, } 54 \\
\text { Administrativo, } 39 \\
\text { Administrativo, } 38 \\
\text { Secretaria, } 55 \\
\text { Secretaria, } 40 \\
\text { Secretaria, } 33\end{array}$ & $\begin{array}{l}\text { Supervisor, } 62 \\
\text { Supervisor, } 44 \\
\text { Supervisor, } 35\end{array}$ & $\begin{array}{l}9 \text { casos } \\
\text { Hombres: } 6 \\
\text { Mujeres: } 3\end{array}$ \\
\hline Proletariado: & $\begin{array}{l}\text { Cartero, } 64 \\
\text { Mantenimiento, } 43 \\
\text { Limpiadora, } 33 \\
\text { Limpiadora, } 34 \\
\text { Limpiadora, } 55 \\
\text { Limpiadora, } 56\end{array}$ & $\begin{array}{l}\text { Conductor, } 43 \\
\text { Operador, } 39 \\
\text { Guardia, } 34 \\
\text { Jornalero, } 25 \\
\text { Jornalero, } 22 \\
\text { Limpiadora, } 57 \\
\text { Limpiadora, } 54\end{array}$ & $\begin{array}{l}13 \text { casos } \\
\text { Hombres: } 7 \\
\text { Mujeres: } 6\end{array}$ \\
\hline $\begin{array}{l}\text { N. }{ }^{\circ} \text { de casos para } \\
\text { cada campo: }\end{array}$ & $\begin{array}{l}15 \text { casos } \\
\text { Hombres: } 7 \\
\text { Mujeres: } 8\end{array}$ & $\begin{array}{l}15 \text { casos } \\
\text { Hombres: } 12 \\
\text { Mujeres: } 3\end{array}$ & $\begin{array}{l}\text { Total: } 30 \text { casos } \\
\text { Hombres: } 19 \\
\text { Mujeres: } 11\end{array}$ \\
\hline
\end{tabular}

individual están más cristalizadas a partir de la inserción en el mundo laboral, ya que este funciona como un potente estructurador de la subjetividad.

El diseño muestral contemplaba la realización de relatos de vida a partir de cuatro criterios muestrales fundamentales: la clase social, el campo social, la generación y el género. Se consideraron tres clases sociales: el proletariado, compuesto por agentes que realizan trabajos manuales; las clases medias, conformadas por los agentes que realizan trabajos no manuales pero rutinarios, y las clases superiores, formadas por los agentes que realizan el trabajo intelectual.

La muestra también está dividida entre los dos campos sociales más diferentes que se pudieron estudiar en la región: el campo universitario, que está dominado por el capital cultural, y el campo minero, que, además de ser el más representativo de la región de Antofagasta, está dominado por el capital económico.

El criterio generacional resulta fundamental para el análisis de la subjetividad política, que es más importarte aún en el caso de Chile, donde se produjeron severos cambios sociopolíticos en un breve periodo histórico. Sintetizando, el intento de revolución socialista de la Unidad Popular (19701973), el golpe de Estado y la contrarrevolución neoliberal de la dictadura militar (1973-1990) y la posterior transición a la democracia con los gobiernos pospinochetistas (1990-2013). 
Finalmente, el criterio de género también resulta indispensable para el estudio de la subjetividad política. De hecho, la incorporación del género supone el primer y más potente proceso de estructuración de los cuerpos y de las mentes (Bourdieu, 2003a). Lamentablemente, pese a que el diseño muestral original contemplaba el mismo número de casos para ambos géneros, solo se ha podido alcanzar este objetivo para el campo universitario, ya que el campo minero está fuertemente masculinizado.

\section{Región de Antofagasta}

Esta región se encuentra situada en el norte de Chile, en pleno desierto de Atacama. Limita al norte con la región de Tarapacá, al sur con la región de Atacama, al noreste con Bolivia, al sureste con Argentina y al oeste con el océano Pacífico. Su superficie representa el $17 \%$ del total de Chile, aunque su población (569.634 habitantes) representa apenas el 3,4\% de la población del país (CASEN, 2009). La mayor parte de esta población se concentra en la ciudad de Antofagasta con 348.669 habitantes y en la de Calama con 147.886 con habitantes (censo del año 2012).

Actualmente, en la región de Antofagasta se extrae el 50\% de todo el cobre chileno. Chile es el mayor productor mundial, con el 35\% del total (COCHILCO). El sector minero representa el 55\% del PIB regional (Banco Central de Chile), emplea directamente al $14,6 \%$ de su población activa y, además, atrae a un gran número de trabajadores del resto del país (Aroca y Atienza, 2008). Como consecuencia de lo anterior, el ingreso de la región es el segundo mayor del país, después de la Región Metropolitana.

Sin embargo, la región padece una representación social negativa en el resto de Chile, que está relacionada con su distanciamiento espacial, con su geografía desértica, con su situación fronteriza y con los estereotipos de los trabajadores mineros (Rodrigo y Atienza, 2014).

\section{Análisis}

Dada la multiplicidad empírica de formas de $s e r^{8}$ producidas por las distintas combinaciones posibles de experiencias vitales ${ }^{9}$ o condiciones de existencia, hemos renunciado a reconstruir habitus políticos completos, es decir, tipologías que contengan todas las disposiciones políticas y todas las situaciones sociales que las han generado. Para facilitar el análisis y ganar claridad expositiva, hemos decidido reconstruir habitus políticos parciales, esto es, tipologías construidas a partir de una determinada experiencia o situación social concreta, relacionándola con las disposiciones políticas que esta produce. Se advierte, por tanto, que, para explicar y comprender todas las disposiciones políticas de un agente, habría que combinar distintos habitus políticos.

8. Aunque no todas las combinaciones de disposiciones políticas son igualmente probables.

9. Igualmente, no todas las combinaciones de experiencias sociales objetivas son igualmente probables. 
Gráfico 1. Mapa de Chile

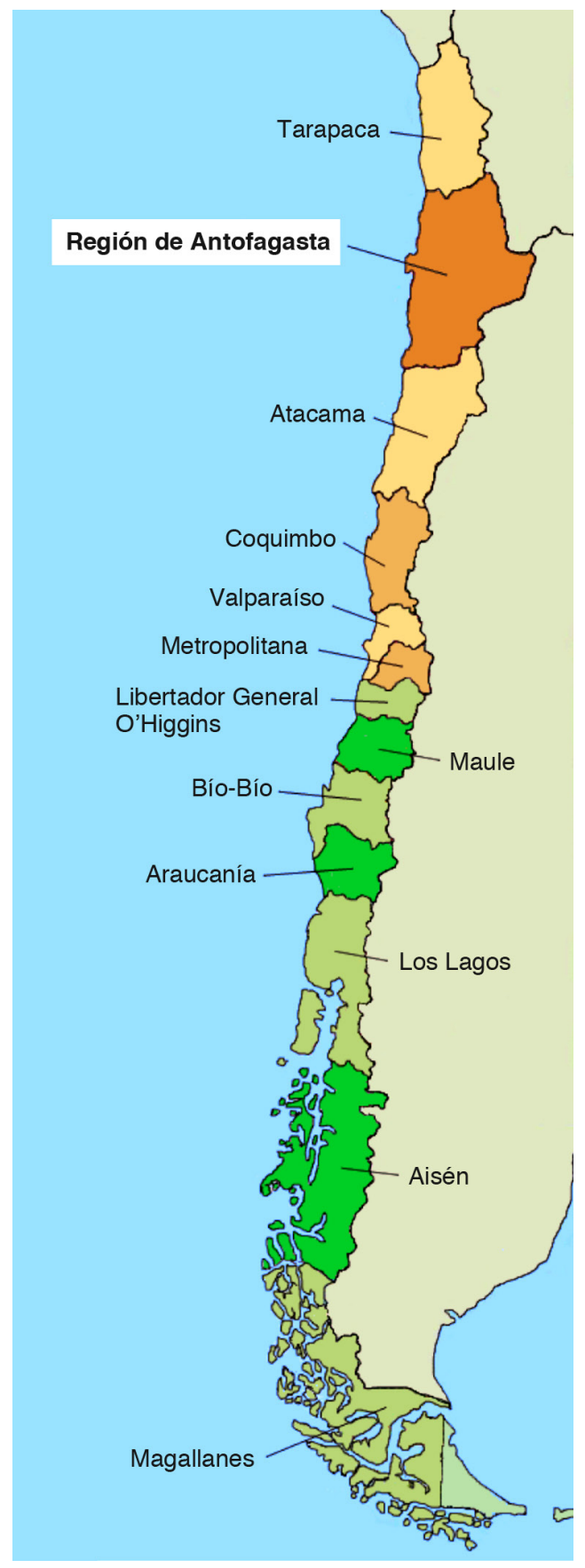


Hemos organizado la presentación de los habitus políticos reconstruidos a partir de las cuatro experiencias vitales que han mostrado una mayor capacidad para estructurar la subjetividad política. Estas son: el posicionamiento familiar en el conflicto histórico, la clase social, la trayectoria social y la trayectoria territorial.

\section{Experiencia de vida I. El posicionamiento familiar en el conflicto histórico}

El posicionamiento político con que se enfrentaron las familias de los entrevistados a lo que hemos denominado el conflicto histórico ${ }^{10}$ ha resultado, en prácticamente todos los casos, un hecho determinante en la estructuración de su subjetividad política, muy especialmente en su identificación política. En los casos excepcionales en los que la familia no ha sido el principal agente socializador político, la universidad, las fuerzas armadas o la mina aparecen ejerciendo esta función.

\section{El habitus conservador-pinochetista}

Se caracteriza por proceder de familias políticamente conservadoras, que rechazaron al gobierno de la Unidad Popular y que apoyaron tanto el golpe de Estado como la posterior dictadura militar. Este habitus rechaza la legitimidad del gobierno de la Unidad Popular y defiende la necesidad del golpe de Estado y de la dictadura militar (discurso pinochetista), además de mantener posiciones nacionalistas. Bascula entre el rechazo total a las protestas sociales y su rechazo parcial. Atribuye la posición social de los chilenos a su esfuerzo personal (discurso meritocrático). Finalmente, se muestra muy preocupado por la seguridad física en general y por la delincuencia y el desorden social en particular.

\section{El habitus socialista-allendista}

A diferencia del anterior, este habitus se produce fundamentalmente durante la socialización política secundaria. Puede existir una predisposición familiar anterior, pero, aunque descender de una familia allendista o represaliada genera una fuerte identificación afectiva con la izquierda y un rechazo hacia los militares, no es condición necesaria ni suficiente para producir este habitus, que se estructura durante una socialización política secundaria asociada necesariamente con agentes políticos socialistas. Dicha socialización se puede producir en la universidad ${ }^{11}$, en la fábrica, en la mina, en el sindicato, en el Partido Comunista o durante una participación prolongada en protestas

10. Nos referimos al periodo que comprende desde el gobierno de la Unidad Popular (19701973) hasta la dictadura militar (1973-1990), pasando por el golpe de Estado (1973).

11. Especialmente durante los gobiernos de Frei Montalva (1964-1970) y de Salvador Allende (1970-1973). 
sociales o laborales. Este habitus se presenta en clases superiores y medias que cuentan con un volumen significativo de capital lingüistico. Se caracteriza por identificarse con la coalición Juntos Podemos Más ${ }^{12}$ y por adoptar posiciones discursivas críticas. Defiende la legitimidad del gobierno de la Unidad Popular y sus políticas, rechazando el golpe de Estado, la dictadura militar y el modelo neoliberal heredado (discurso allendista), además de mantener posiciones antinacionalistas. Se considera al sector minero vital para el desarrollo de Chile, definiendo la explotación actual como una usurpación de las corporaciones multinacionales al país y del gobierno chileno a las regiones mineras (discurso del doble expolio). Trabaja, además, por la recuperación de las protestas sociales como medio de participación política. Defiende que la posición social de los chilenos se debe a su origen social y no al esfuerzo (discurso hereditario), siendo especialmente crítico con la reproducción social de las élites económicas. Es el habitus que mejor representa la decepción y la frustración con la clase política (discurso de la decepción con la política) y el cansancio en la participación política. Los problemas sociales que más le preocupan son la desigualdad social y el sistema educativo, al que consideran reproductor.

\section{El habitus disonante}

Se genera cuando distintas figuras importantes para el agente (familiares o del grupo de pares) tienen posiciones enfrentadas e irreconciliables sobre el conflicto histórico. En esta situación, el agente evita el enfrentamiento con ambos «bandos» inhibiéndose en el conflicto. Dicha solución requiere la utilización de un conjunto de mecanismos de defensa y de posiciones discursivas. Este habitus se caracteriza fundamentalmente por la inhibición política, rechaza tanto el posicionamiento político como la valoración del suceso y afirman no votar o hacerlo en blanco. En algunos casos, se recurre a la negación, afirmándose que el conflicto no tuvo importancia o que no se comprenden las razones del enfrentamiento. En otros casos, especialmente en las clases superiores, se recurre a la intelectualización, argumentado que la complejidad sociohistórica del suceso impide tomar partido por una de las facciones enfrentadas, o que lo que corresponde a las generaciones posteriores al conflicto es analizarlo en profundidad para evitar que se repita, pero no posicionarse en él. Utiliza, además, un conjunto de argumentos para reducir la disonancia mediante la racionalización del conflicto; se enfatiza su inevitabilidad al atribuirlo a la situación social y no a la responsabilidad de los actores. Se afirma también que ambas facciones fueron igualmente responsables del quiebre histórico (tesis de la corresponsabilidad) y que se causaron un daño similar (tesis de equivalencia).

12. Coalición de partidos de izquierda liderada por el Partido Comunista de Chile y por la Izquierda Cristiana. 
Cuadro 2. Habitus políticos estructurados a partir del posicionamiento familiar en el conflicto histórico

\begin{tabular}{|c|c|c|c|c|}
\hline Orden social & Crítico & Adap & tativos & Regresivo \\
\hline Habitus & Socialista-allendista & Disonante & Utilitarista & Conservador-pinochetista \\
\hline Experiencias & $\begin{array}{l}\text { Socialización política } \\
\text { secundaria con agentes } \\
\text { socialistas. }\end{array}$ & $\begin{array}{l}\text { Conflicto político entre } \\
\text { figuras próximas. }\end{array}$ & $\begin{array}{l}\text { Familia vulnerable y poco } \\
\text { afectada por el conflicto } \\
\text { histórico. }\end{array}$ & $\begin{array}{l}\text { Familia políticamente } \\
\text { conservadora. }\end{array}$ \\
\hline Disposiciones & $\begin{array}{l}\text { Identificación con } \\
\text { Juntos Podemos Más. } \\
\text { Discursos: } \\
\text { — Allendista. } \\
\text { — Antinacionalista. } \\
\text { — Del doble expolio. } \\
\text { - Hereditario. } \\
\text { - De la decepción } \\
\text { con la política. } \\
\text { Preocupación social: } \\
\text { — Desigualdad social. } \\
\text { — Educación. }\end{array}$ & $\begin{array}{l}\text { Evitación del posicionamiento } \\
\text { en el conflicto mediante } \\
\text { mecanismos } \\
\text { de defensa y posiciones dis- } \\
\text { cursivas. } \\
\text { Mecanismos de defensa: } \\
\text { - Inhibición política. } \\
\text { — Racionalización. } \\
\text { — Negación. } \\
\text { — Intelectualización. } \\
\text { Posiciones discursivas: } \\
\text { — Tesis de la inevitabilidad. } \\
\text { — Tesis de la corresponsa- } \\
\text { bilidad. } \\
\text { — Tesis de la equivalencia. }\end{array}$ & $\begin{array}{l}\text { No tiene identificación con } \\
\text { ninguna de las facciones del } \\
\text { conflicto. } \\
\text { Alta capacidad de adaptación } \\
\text { a distintos regímenes políticos } \\
\text { y grupos sociales. } \\
\text { Posicionamiento político } \\
\text { determinado por el interés. }\end{array}$ & $\begin{array}{l}\text { Identificación con la } \\
\text { Coalición por el Cambio. } \\
\text { Discursos: } \\
\text { - Pinochetista. } \\
\text { - Nacionalista. } \\
\text { - Del rechazo al } \\
\text { conflicto. } \\
\text { - Meritocrático. } \\
\text { Preocupación social: } \\
\text { - Delincuencia. } \\
\text { - Desorden social. }\end{array}$ \\
\hline
\end{tabular}

\section{El habitus utilitarista}

Está determinado por una socialización política familiar de tipo utilitarista como consecuencia principalmente de dos experiencias: en primer lugar, la familia no fue significativamente afectada, ni positiva ni negativamente ${ }^{13}$, por el golpe de Estado y la posterior dictadura militar. Y, en segundo lugar, la familia padecía una situación de vulnerabilidad social y dependencia económica, por lo que tomar un claro posicionamiento político en un contexto de fuerte conflicto social suponía, y así fue percibido, un riesgo socioeconómico muy alto, pues exponía a sus miembros a una potencial pérdida de beneficios. La ausencia de un vínculo afectivo con la izquierda o con la derecha dota al habitus utilitarista de una gran capacidad de adaptación a los distintos momentos históricos que ha vivido el país (la dictadura militar y la democracia actual) y de mucha libertad en el establecimiento de relaciones con distintos grupos sociales (grupos políticos o clases sociales). Por lo anterior, las posiciones discursivas que ha mantenido sobre lo político han sido muy flexibles y bien adaptadas a los intereses de cada momento.

\section{Experiencia de vida II. La clase social}

La clase social a la que pertenecen los entrevistados, y muy especialmente la clase social en la que fueron socializados (clase de origen), han resultado ser

13. Nos referimos a familias que ni se sintieron «salvadas» por los militares, ni sufrieron directamente la represión. 
elementos esenciales en la estructuración de la subjetividad política. Disposiciones tan relevantes como la autovaloración, la autonomía social, la respuesta a las relaciones de dominación y los problemas sociales percibidos están determinadas por esta experiencia.

\section{El habitus de burgués alarmado ${ }^{14}$}

Este habitus se generó en personas que pertenecieron a familias burguesas durante el gobierno de la Unidad Popular. Las políticas socialistas de este gobierno, especialmente la nacionalización de empresas, el control de precios y la reforma agraria, junto con las acciones sociales que llevaron a cabo sus partidarios, como la socialización de empresas y la apertura forzosa de almacenes, produjeron una grave crisis en las familias burguesas, que vieron claramente amenazada su reproducción como clase. Estas familias comparten un nudo biográfico que se forjó por el miedo y la inseguridad (económica y física) que sufrieron en aquel momento histórico. Dicha experiencia estructuró de forma determinante su subjetividad política. En aquel contexto, el golpe de Estado fue percibido como un rescate ante un exterminio social inminente, $y$ la dictadura militar como la restauración del orden natural y como el dispositivo necesario para su vigilancia ${ }^{15}$. Este habitus se caracteriza por una defensa cerrada del golpe de Estado y de la dictadura militar y por un rechazo total a las protestas sociales, a las que se teme. Además, está determinado por un gran volumen de capital global (económico, cultural, social y simbólico) como consecuencia de su clase de origen, que le permite tener una autovaloración muy positiva, una gran seguridad, tanto en sus capacidades como en sus relaciones interpersonales, $\mathrm{y}$ un alto grado de independencia social ${ }^{16}$.

\section{El habitus de descendiente del burgués alarmado}

Los hijos de la burguesía alarmada, que se encuentra actualmente en torno a la treintena (generación de los 80 ), no han vivido en primera persona el conflicto histórico. En lo familiar, han recibido una socialización política pinochetista, pero en el resto del espacio social se han visto obligados a reconocer y tomar conciencia de al menos dos características reprobables del «gobierno de Pinochet» ${ }^{17}$ : la violación de derechos humanos y su autoritarismo. Este re-conocimiento de la dictadura militar se realizó en el espacio institucional mediante el sistema escolar y la televisión pública; también en los espacios de

14. En el sentido de asustado, pero también en el de «al-arma».

15. De hecho, se representa a Pinochet como «salvador» y/o "guardián».

16. Sus trayectorias vitales muestran una disposición a la independencia, como capacidad objetiva y como necesidad subjetiva, que atraviesa todas sus relaciones sociales y les ha permitido tener un control significativo de su existencia. Han podido elegir estudios, trabajos, parejas (o la soltería), así como las ciudades en las que han vivido.

17. La derecha política chilena evita el término dictadura sustituyéndolo por gobierno o régimen. De igual manera, se refieren al golpe de Estado militar como "pronunciamiento militar». 
sociabilidad mediante la interacción con pares (vecinos o compañeros escolares) que eran hijos de exiliados ${ }^{18}$, y en las estancias en el extranjero que, posibilitadas por su clase social, les han permito conocer los discursos exteriores sobre el pinochetismo. Este re-conocimiento supone el cuestionamiento tanto del golpe de Estado como de la dictadura militar (discurso conservador) y un distanciamiento irremediable de la posición política familiar (discurso pinochetista). Cuando este distanciamiento político se torna conflictivo, puede resolverse mediante la inhibición política, es decir, generando un habitus disonante. Por otro lado y al igual que sus ascendientes, se caracterizan por una elevada autoestima, seguridad e independencia social derivadas de su alto volumen de capital global.

\section{El habitus empresarial}

Está determinado por su posición en el modo de producción, por ello, para su estructuración, la clase de origen es menos relevante que la clase social actual. Se caracteriza por utilizar un marco de sentido mercantil para interpretar lo político. Se demanda del Estado mejoras en los factores productivos, principalmente una mejor capacitación de los trabajadores de la región y el aumento de la inmigración para asegurar mano de obra abundante y a buen precio (discurso de la necesidad productiva). Se defiende, además, el mérito personal como explicación de la posición social (discurso meritocrático). Como el resto de habitus de las clases superiores, este posee una excelente autovaloración, una gran seguridad y una marcada independencia social consecuencia de su elevado volumen de capital global.

\section{El habitus profesional}

Está generado por una larga inversión escolar que tiene como punto de partida las clases medias o superiores y por una ocupación que requiere titulación universitaria. Se caracteriza por una alta autoestima, seguridad e independencia social procedente de su elevado volumen de capital (principalmente cultural). Respecto a los problemas sociales, está molesto y preocupado por los altos costes de la educación universitaria que su familia ha tendido que abonar y que él tendrá que pagar necesariamente a sus hijos, ya que este es su único medio de reproducción social.

\section{El habitus de supervisor}

Es un subtipo de habitus profesional que cumple las funciones de supervisión de trabajadores en el campo minero. Se caracteriza por identificarse con los

18. El regreso de los exiliados se produce en la década de los 80 , todavía durante la dictadura militar. Esto posibilitó la interacción social entre las familias exiliadas que llegaban de Europa y el resto de los chilenos. 
Cuadro 3. Habitus políticos estructurados a partir de las clases superiores

\begin{tabular}{|c|c|c|c|c|c|}
\hline Orden social & Regresivo & \multicolumn{4}{|c|}{ Adaptativos } \\
\hline Habitus & Burgués alarmado & $\begin{array}{l}\text { Descendiente de } \\
\text { burgués alarmado }\end{array}$ & Empresarial & Profesional & Supervisor \\
\hline Experiencias & $\begin{array}{l}\text { Vivió en familia burgue- } \\
\text { sa durante el gobierno } \\
\text { de la UP. }\end{array}$ & $\begin{array}{l}\text { Procede de familia bur- } \\
\text { guesa, pero no vivió el } \\
\text { conflicto histórico. }\end{array}$ & $\begin{array}{l}\text { Posición social actual } \\
\text { de empresario. }\end{array}$ & $\begin{array}{l}\text { Procede de familias } \\
\text { de clases medias o } \\
\text { superiores y ha reali- } \\
\text { zado una importante } \\
\text { inversión académica. }\end{array}$ & $\begin{array}{l}\text { Profesionales con } \\
\text { funciones de supervi- } \\
\text { sión de trabajadores } \\
\text { en el campo minero. }\end{array}$ \\
\hline $\begin{array}{l}\text { Volumen de } \\
\text { capital global }\end{array}$ & Alto & Alto & Alto & Alto & Alto \\
\hline \multirow[t]{2}{*}{ Disposiciones } & $\begin{array}{l}\text { Alta autovaloración } \\
\text { y anatomía. }\end{array}$ & $\begin{array}{l}\text { Alta autovaloración } \\
\text { y anatomía. }\end{array}$ & $\begin{array}{l}\text { Alta autovaloración } \\
\text { y anatomía. }\end{array}$ & $\begin{array}{l}\text { Alta autovaloración } \\
\text { y anatomía. }\end{array}$ & $\begin{array}{l}\text { Alta autovaloración } \\
\text { y anatomía. }\end{array}$ \\
\hline & $\begin{array}{l}\text { Discursos: } \\
\text { - Pinochetista. } \\
\text { - Rechazo al conflicto. } \\
\text { Preocupación: } \\
\text { — Inseguridad. }\end{array}$ & $\begin{array}{l}\text { Discurso: } \\
\text { — Conservador. } \\
\text { Preocupación: } \\
\text { — Evitación de nuevos } \\
\text { conflictos } \\
\text { sociopolíticos. }\end{array}$ & $\begin{array}{l}\text { Discursos: } \\
\text { — Necesidad } \\
\text { productiva. } \\
\text { — Meritocrático. } \\
\text { Preocupación: } \\
\text { - Escasez o precio } \\
\text { de los factores } \\
\text { productivos. }\end{array}$ & $\begin{array}{l}\text { Discurso: } \\
\text { — Meritocrático. } \\
\text { Preocupación: } \\
\text { — Costo de la } \\
\text { educación. }\end{array}$ & $\begin{array}{l}\text { Discursos: } \\
\text { — Inversión } \\
\text { extranjera. } \\
\text { — Necesidad } \\
\text { productiva. } \\
\text { Preocupación: } \\
\text { — Identificación } \\
\text { con los intereses } \\
\text { de la empresa. }\end{array}$ \\
\hline
\end{tabular}

intereses empresariales. Defiende decididamente a las multinacionales mineras extranjeras mostrándose totalmente contrario a la renacionalización o a la imposición de un canon al sector (discurso de inversión extranjera). Apoya también un incremento de la inmigración para garantizar la actividad del sector minero (discurso de la necesidad productiva), por entender que los inmigrantes son más productivos y confiables que los nacionales.

\section{El habitus de clase media}

Se produce en las personas que provienen de familias de clases medias, independientemente de cual haya sido su trayectoria social (ascendente, horizontal o descendente). Es decir, lo podemos encontrar en personas que actualmente pertenecen al proletariado, a las clases superiores o a las clases medias, ya que se estructura durante la socialización primaria. Se caracteriza por ser altivo en sus relaciones sociales, exigente respecto a sus derechos y proactivo en la persecución de sus intereses. Tiende a perseguir cierto grado de autonomía social, especialmente económica, aunque, a diferencia de las clases superiores, en la mayoría de los casos, se carece de la capacidad suficiente (volumen de capital) para mantenerla. Manifiesta preocupación por los problemas familiares de salud ${ }^{19} \mathrm{y}$ molestia

19. La sanidad pública chilena no es universal ni gratuita y tampoco cubre todas las enfermedades, por lo que el endeudamiento familiar es habitual para afrontar las enfermedades catastróficas. 
por la calidad del sistema público de salud que se ven obligados a utilizar ${ }^{20}$. Sin embargo, las características más distintivas de este habitus son la insumisión y el esfuerzo de distinción social. A diferencia de las clases superiores, el habitus de clase media percibe las relaciones de dominación social (clasismo, racismo y sexismo) y se defiende contra ellas mostrándose insumiso. Además de esto, el habitus de clase media realiza un esfuerzo continuo de diferenciación social del proletariado. Esta diferencia consiste en un tipo de dignidad de la que el proletariado carecería y que impediría a este habitus ser de algunas formas o hacer algunas cosas que sí podrían ser o hacer los proletarios. Esta dignidad se reafirma y se reivindica con fuerza cuando perciben que han sido enclasados (o ante el riesgo de serlo) junto al proletariado por parte de las clases superiores. Estas disposiciones (altivez, exigencia, proactividad, insumisión y distinción social), que lo distinguen de las clases superiores, tienen un claro carácter defensivo o reivindicativo que responde al hecho de que su posición social nunca está asegurada, siempre es provisional y discutible y siempre necesita ser reivindicada. En resumen, son disposiciones para defender un espacio social conquistado, pero que no está consolidado.

\section{El habitus minero-obrero}

Se produce en los descendientes de familias mineras u obreras que también fueron socializados laboral y políticamente en las minas o en las fábricas. Muchas de estas familias sufrieron algún grado de represión durante la dictadura militar por su activismo sindical y/o político. Este habitus se caracteriza por ser obrerista, poseer conciencia de clase y representar las relaciones económicas como un conflicto entre clases sociales. El activismo sindical, la participación en protestas laborales y una militancia (con distintos grados de implicación) en los partidos políticos obreristas (Partido Socialista y Partido Comunista) son los elementos fundamentales de su comportamiento político y las prácticas generadoras de su identidad de clase. Al igual que el habitus de clase media, es altivo en sus relaciones sociales, especialmente en las laborales, exigente en la reivindicación de sus derechos laborales e insumiso en las relaciones laborales de dominación ${ }^{21}$. Respecto a su posición en el conflicto histórico, se caracteriza por reproducir el discurso allendista o concertacionista ${ }^{22}$. Es crítico con la actual política minera (discurso del doble expolio), mostrándose partidario de la renacionalización del sector o de la imposición de un canon, y defiende la sindicalización y el conflicto laboral para evitar la explotación empresarial. Argumenta, además, que la posición social de los chilenos viene determinada

20. En general, no tienen ingresos suficientes para acceder a la salud privada.

21. El habitus minero-obrero percibe y se defiende de las relaciones de dominación y explotación de tipo laboral, pero no de otros tipos de dominación y explotación, como la de género o la racial.

22. A diferencia del discurso allendista, se apoya a la coalición política de centro y de centroizquierda (Concertación de Partidos por la Democracia) que siguieron a la dictadura militar (1990-2010), en especial al gobierno de Michelle Bachelet. 
por su origen social (discurso hereditario) y se muestra preocupado por el problema de la desigualdad social y por la pobreza. Por último, hay que señalar que rechaza la inmigración laboral (discurso xenofóbico laboral), por percibirla como un riesgo económico. Podemos observar, al igual que en el habitus de clase media, la función manifiestamente defensiva de las disposiciones políticas de este habitus, pero, a diferencia del primero, estas disposiciones se circunscriben principalmente a las relaciones laborales (no al resto de relaciones sociales) y pasan fundamentalmente por estrategias grupales solidarias, no individuales o familiares. Entendemos que estas diferencias se deben a una menor capacidad individual o familiar, producto de un bajo volumen de capital global, y a unas relaciones sociolaborales más hostiles que amenazan continuamente con revertir las conquistas alcanzadas.

\section{El habitus proletario}

Se genera en los descendientes de las familias proletarias ${ }^{23}$ o pobres, independientemente de cuál haya sido su trayectoria social posterior (horizontal o ascendente). Las personas que han desarrollado este habitus tienen en común el haber experimentado, durante su socialización primaria, unas condiciones de existencia muy precarias marcadas por la pobreza, la fatalidad familiar (abandono o maltrato del padre, accidentes, muertes, enfermedades), el trabajo infantil y, en el caso de la mujeres, el maltrato y/o la explotación de género llevada a cabo por el padre, los hermanos, la pareja o el jefe. A consecuencia de esta vulnerabilidad social, también experimentaron una fuerte dependencia social, tanto de instituciones (administraciones públicas, iglesias, etc.) como de ciertas figuras cercanas (familiares mejor posicionados, políticos locales, superiores laborales, etc.), que ejercieron sobre ellos un rol protector y proveedor. En resumen, estas personas fueron socializadas en la pobreza, en la explotación y en la dependencia, en una situación de gran inseguridad existencial, siendo siempre más acusada en las mujeres, por haber sido estas doblemente explotadas. Por lo anterior, el habitus proletario se caracteriza por una autovaloración muy negativa y por unas expectativas sociolaborales muy bajas. En las relaciones laborales, se distingue por una disposición a la sumisión, esto es, por no percibir ni rechazar las relaciones sociales de dominación (laboral, de clase, de género o racial) y por la adopción del servilismo como estrategia laboral, es decir, la obediencia incondicional a los superiores jerárquicos, el esfuerzo por superar las expectativas de estos, la demostración de completa disponibilidad y la represión total del conflicto. Respecto al resto de relaciones sociales, se caracteriza por el temor y la evitación del posicionamiento discursivo en general y político en particular (discurso del miedo a protestar), por la atribución de la posición social al esfuerzo personal y por la idealización de las clases medias y superiores

23. Excepto las pertenecientes al sector minero e industrial, donde se genera el habitus mineroobrero. 
Cuadro 4. Habitus políticos estructurados a partir de las clases medias y proletarias

\begin{tabular}{|c|c|c|c|}
\hline Orden social & & Críticos & Adaptativo \\
\hline Habitus & De clase media & Minero-obrero & Proletario \\
\hline Experiencias & $\begin{array}{l}\text { Provenientes de familias } \\
\text { de clases medias. }\end{array}$ & $\begin{array}{l}\text { Provenientes de familias mineras } \\
\text { u obreras que han seguido la } \\
\text { misma trayectoria laboral. }\end{array}$ & $\begin{array}{l}\text { Proveniente de familias proletarias } \\
\text { o pobres. }\end{array}$ \\
\hline $\begin{array}{l}\text { Volumen de } \\
\text { capital global }\end{array}$ & Medio & Medio-bajo & Bajo \\
\hline Disposiciones & $\begin{array}{l}\text { Alta autovaloración } \\
\text { y búsqueda de autonomía } \\
\text { social. } \\
\text { Insumisión ante las relacio- } \\
\text { nes de dominación. } \\
\text { Esfuerzo de distinción } \\
\text { social. } \\
\text { Preocupación: } \\
\text { - Problemas de salud } \\
\quad \text { (endeudamiento). }\end{array}$ & $\begin{array}{l}\text { Autovaloración media e } \\
\text { insumisión laboral. } \\
\text { Discursos: } \\
\text { - Allendista o concertacionista. } \\
\text { — Del doble expolio. } \\
\text { — Hereditario. } \\
\text { - Xenofobia laboral. } \\
\text { Preocupación: } \\
\text { - Desigualdad social. } \\
\text { — Pobreza. }\end{array}$ & $\begin{array}{l}\text { Autovaloración baja. } \\
\text { Sumisión y servilismo. } \\
\text { Dependencia social. } \\
\text { Discursos: } \\
\text { — Miedo a protestar. } \\
\text { - Meritocrático. } \\
\text { - Xenofóbico laboral (hombres). } \\
\text { - Xenofóbico delictivo (mujeres). } \\
\text { Preocupaciones: } \\
\text { - Vivienda y salarios. } \\
\text { - Pobreza, droga y delincuencia. }\end{array}$ \\
\hline
\end{tabular}

(discurso meritocrático). Existe también la disposición a establecer relaciones de dependencia en demanda de ayuda, protección u orientación y a identificarse con las posiciones políticas de estas figuras protectoras y proveedoras. Al igual que el habitus minero-obrero, este también rechaza la inmigración, ya sea por su riesgo laboral (discurso xenofóbico laboral) o por su riesgo delictivo (discurso xenofóbico delictivo). Este habitus está preocupado principalmente por problemas materiales como el de la vivienda o los bajos salarios y por los problemas relacionados con la inseguridad (física y económica), como la pobreza, la droga y la delincuencia que habita sus barrios. A diferencia del habitus de clase media y del habitus minero-obrero, las disposiciones políticas del habitus proletario (sumisión, servilismo, inhibición política, meritocracia y dependencia) no tienen un carácter defensivo (excepto la xenofobia), sino claramente adaptativo. Se trata de un sometimiento naturalizado a los dominantes que busca conseguir su aprecio como única estrategia para obtener cierta seguridad material. Carece tanto de la capacidad individual y familiar (capital global) de las clases medias como de las posibilidades de acción colectiva de la clase obrera-minera.

Podemos organizar los anteriores habitus políticos a partir de dos dimensiones: el volumen de capital global (eje vertical) y la posición frente al orden social (eje horizontal). Así, en la parte superior del mapa, tenemos a los habitus que requieren de un alto volumen de capital y, en la parte inferior, a los que se han generado a partir de un bajo volumen de capital. En la parte derecha del mapa, están los habitus que proponen un cambio de orden regresivo, en la zona central, los habitus mejor adaptados al presente orden social neoliberal y en la parte izquierda del mapa, están los habitus más críticos y reivindicativos. 
Mapa topológico 1. Habitus políticos estructurados por la clase social

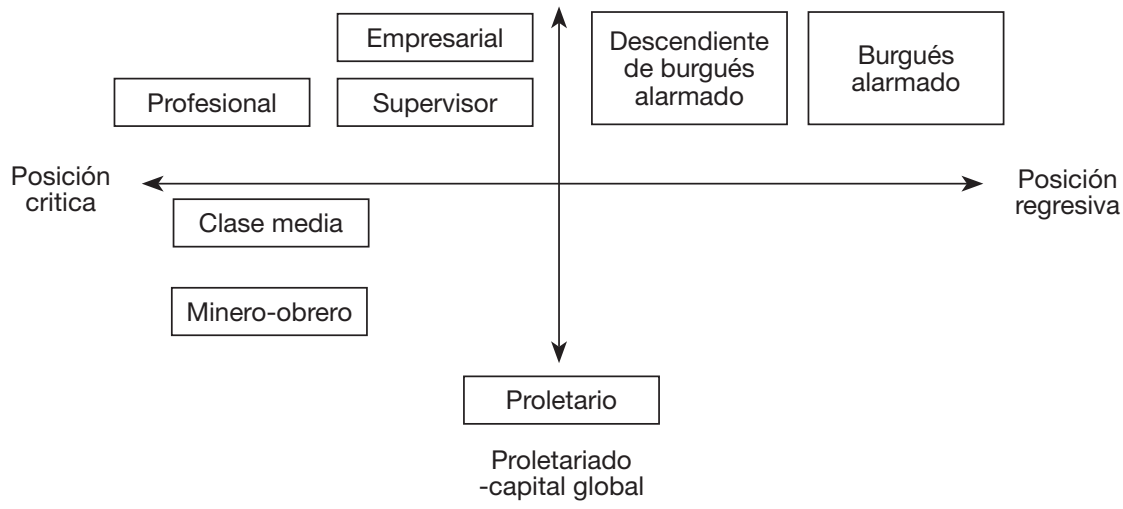

Experiencia de vida III. La trayectoria social

La trayectoria social (ascendente, descendente $\mathrm{u}$ horizontal) que han realizado los entrevistados desde su clase de origen hasta su posición social actual se ha mostrado también como una experiencia estructuradora de la subjetividad política. El desplazamiento de las posiciones políticas, la orientación hacia el pasado (nostalgia) o hacia el futuro (optimismo) aparecen relacionados con esta experiencia.

\section{El habitus hidalgo ${ }^{24}$}

Este habitus se produce en los hijos de familias de clases superiores o medias que han sufrido una trayectoria social descendente hasta el proletariado. En estos casos, los agentes y sus familias de origen fracasaron en la consecución de la reproducción social, esto es, que los hijos se mantengan en la misma clase social que sus padres. Este habitus mantiene las disposiciones de su clase media de origen, es decir, sigue siendo altivo en sus relaciones sociales, exigente respeto a sus derechos, con tendencia a buscar la autonomía económica para mejorar su situación social y se muestra insumiso ante las relaciones de dominación, buscando establecer relaciones horizontales o de igualdad con sus superiores jerárquicos. Incluso mantienen el esfuerzo de diferenciación social del proletariado (típico de las clases medias) aunque ahora pertenezcan a esta misma clase social, para ello, intentan mantener su dignidad en el ámbito laboral rechazando hacer ciertos trabajos o ser tratados o llamados de ciertas maneras. En el ámbito social, hay un esfuerzo por mantener algunas propiedades típicas de las clases medias, como la vivienda propia, el automóvil, vivir en

24. En términos bourdieunianos, sería un agente que tiene más capital simbólico (estatus) que económico. 
Cuadro 5. Habitus políticos estructurados a partir de la trayectoria social

\begin{tabular}{|c|c|c|}
\hline Orden social & Adaptativos & Regresivo \\
\hline Habitus & Optimista & Hidalgo \\
\hline Experiencias & Ascenso social. & $\begin{array}{l}\text { Descenso social, desde las } \\
\text { clases medias y superiores } \\
\text { hasta el proletariado. }\end{array}$ \\
\hline Volumen de capital global & Aumentó. & Disminuyó. \\
\hline \multirow[t]{2}{*}{ Disposiciones } & $\begin{array}{l}\text { Mantiene disposiciones propias } \\
\text { de la clase de origen. } \\
\text { Adquisición de nuevas disposi- } \\
\text { ciones propias de la clase de } \\
\text { destino. } \\
\text { Sentimiento social. }\end{array}$ & $\begin{array}{l}\text { Mantiene las disposiciones } \\
\text { del habitus de clase media } \\
\text { y la posición política familiar. } \\
\text { Adquisición de nuevas disposi- } \\
\text { ciones obreras sin perder las } \\
\text { disposiciones primarias. }\end{array}$ \\
\hline & $\begin{array}{l}\text { - Optimismo sobre el futuro } \\
\text { personal y de Chile. }\end{array}$ & $\begin{array}{l}\text { Sentimiento social: } \\
\text { - Nostalgia. }\end{array}$ \\
\hline
\end{tabular}

un barrio de clases medias o el habla. Se mantienen las posiciones discursivas de la familia de origen, aunque en los casos en que se ha descendido a un proletariado minero o fabril, se produce una resocialización política mediante los agentes socializadores obreros (compañeros, sindicatos, partidos políticos) y la sociabilidad obrera (en el trabajo, en la protesta laboral y en el ocio) que genera nuevas disposiciones políticas típicamente obreras, como la sindicalización, la representación del mundo laboral como un conflicto entre clases y el obrerismo. Sin embargo, la adquisición de estas nuevas disposiciones no supone el abandono de las antiguas, el habitus realiza el esfuerzo necesario para acomodar las diferentes disposiciones, aunque estas sean lógicamente irreconciliables.

\section{El habitus optimista}

Este habitus se produce en personas que han realizado una trayectoria social ascendente, normalmente, desde el proletariado hacia las clases medias. Se caracteriza por ser optimista sobre su futuro personal y familiar, así como sobre el futuro económico de Chile.

\section{Experiencia de vida IV. La trayectoria espacial}

Finalmente, la trayectoria espacial que han realizado los entrevistados a lo largo de sus vidas también ha resultado ser una experiencia social generadora de subjetividad política. La valoración del modelo social, de los chilenos y de la región de Antofagasta está relacionada con estas vivencias.

\section{El habitus de nativa nostálgica}

Lo encontramos en las mujeres que son originarias de la región de Antofagasta, especialmente entre las clases medias. Se caracteriza por denunciar la degra- 
dación que habría sufrido la región y, en especial, la ciudad de Antofagasta por la llegada de inmigrantes nacionales y suramericanos (discurso xenofóbico delictivo), así como por rememorar una Antofagasta anterior que habría sido mucho mejor. Para este habitus, actualmente, Antofagasta sería una ciudad muy sucia, peligrosa e insociable. Esto sería consecuencia de la llegada masiva de inmigrantes empobrecidos y peligrosos desde Santiago y, actualmente, desde Suramérica que habrían llegado para trabajar en la minería. Estos inmigrantes habrían atraído las drogas, la prostitución y la delincuencia a la región. Además, considera que los inmigrantes no llegan nunca a identificarse con la región, por lo que no se preocuparían por reparar sus viviendas, por la limpieza de la calles o por el mantenimiento de la infraestructura urbana. Frente a esto, se rememora una Antofagasta anterior (de la niñez y de la adolescencia), donde «solo había antofagastinos" y que había sido una ciudad limpia, segura y sociable.

\section{El habitus de inmigrante}

Se genera en los proletarios nacionales y peruanos que emigraron a la región de Antofagasta. Entre estos inmigrantes, ha sido habitual, durante los primeros años en la región, su participación en distintas comunidades religiosas de filiación cristiana (Testigos de Jehová y distintas iglesias protestantes) como estrategia de integración social. Aunque la mayoría de ellos eran católicos poco practicantes en sus lugares de origen, estas sectas cristianas ${ }^{25}$ les permitieron recuperar gran parte de la sociabilidad perdida con la migración (la ruptura de relaciones socioafectivas), lo que les ayudó a superar el asilamiento social. Estas comunidades religiosas les permitieron acceder al capital social necesario, tanto para resolver los problemas materiales más urgentes (vivienda, ropa o alimentación) como para posibilitar su integración laboral ${ }^{26}$ y matrimonial ${ }^{27}$. Después de unos años, los inmigrantes ya integrados socialmente en Antofagasta fueron abandonando progresivamente estas comunidades religiosas. En este sentido, podemos decir que dichas comunidades fueron, para los inmigrantes, equivalentes funcionales de sus comunidades locales, lo que les ayudó a recomponer el tejido social perdido con la migración. Este habitus se caracteriza por realizar una valoración positiva de la región desde la perspectiva económica y climática $^{28}$, a la vez que una valoración negativa desde una perspectiva sociocultural. Manifiestan una mejora en sus condiciones materiales derivadas de mejores condiciones laborales, sin embargo, muestran malestar subjetivo en

25. Se utiliza el concepto secta en su sentido antropológico, esto es, para señalar que nos referimos a grupos religiosos que son minoritarios (frente a la Iglesia católica) y, por tanto, fuertemente cohesionados.

26. Para muchos inmigrantes, la comunidad religiosa supuso la primera red de contactos laborales.

27. Igualmente, muchos inmigrantes conocieron a su pareja actual en estas comunidades religiosas.

28. La climatología es una dimensión esencial para los proletarios, pues realizan gran parte del trabajo en espacios abiertos y a temperatura ambiente. 
Cuadro 6. Habitus políticos estructurados a partir de la trayectoria espacial

\begin{tabular}{|c|c|c|c|}
\hline Orden social & Crítico & Adaptativo & Regresivo \\
\hline Habitus & Socialdemócrata & Inmigrante & Nativa nostálgica \\
\hline Experiencias & $\begin{array}{l}\text { Haber vivido en un país } \\
\text { con Estado de bienestar. }\end{array}$ & $\begin{array}{l}\text { Inmigrante nacional o } \\
\text { suramericano de origen } \\
\text { proletario. }\end{array}$ & $\begin{array}{l}\text { Mujeres originarias de la } \\
\text { región de Antofagasta. }\end{array}$ \\
\hline Disposiciones & $\begin{array}{l}\text { Valoración territorial: } \\
\text { - Negativa. } \\
\text { - Crítica con el modelo } \\
\text { económico chileno. } \\
\text { - Critica a la cultura chi- } \\
\text { lena. }\end{array}$ & $\begin{array}{l}\text { Valoración territorial: } \\
\text { — Ambivalente. } \\
\text { — Valoración positiva } \\
\text { de las dimensiones } \\
\text { económica y climática } \\
\text { de la región. } \\
\text { - Valoración negativa de } \\
\text { la dimensión cultural } \\
\text { de la región. }\end{array}$ & $\begin{array}{l}\text { Valoración territorial: } \\
\text { - Ambivalente. } \\
\text { — Degradación de la } \\
\text { región por la llegada } \\
\text { de inmigrantes. } \\
\text { - Rememoración nostál- } \\
\text { gica de la región. }\end{array}$ \\
\hline
\end{tabular}

forma de incomodidad cultural, soledad y desconfianza social. Los elementos que generan incomodidad cultural serían básicamente tres: la poca fiabilidad de los antofagastinos, la insociabilidad de los nortinos y el carácter más liberal ${ }^{29}$ de la cultura nortina frente a la cultura sureña y peruana (agrarias). Otra disposición que caracteriza al habitus de inmigrante es la acentuación del temor al posicionamiento discursivo, sobre todo político, que ya existe en el habitus proletario. Este habitus realiza un esfuerzo aún mayor para rehuir el posicionamiento, consecuencia sin duda de una situación de mayor inseguridad social.

\section{El habitus socialdemócrata}

Este habitus se generó en los entrevistados que vivieron en países con modelo de Estado de bienestar de tipo europeo, normalmente, en Europa continental o Argentina. Por distintas razones (exilio político, estudios de posgrado o emigración laboral), chilenos de distintas generaciones, clases sociales y posiciones políticas comparten la experiencia de haber vivido en Europa, Argentina o Uruguay. Estos países, pese a sus diferencias culturales y económicas, se caracterizan por compartir un modelo social significativamente distinto al modelo neoliberal chileno. Este habitus se singulariza por criticar al modelo neoliberal y a la cultura chilena a partir de un ejercicio comparativo con los países anteriormente citados. Sobre el modelo socioeconómico, se critica la desigualdad social del país, la incapacidad del Estado y la ausencia de derechos sociales (sanidad, educación y pensiones) y laborales. Por su parte, la crítica cultural describe a la sociedad chilena como conservadora, autoritaria, clasista, racista y machista. En resumen, la experiencia de haber vivido en estados del bienestar culturalmente más progresistas les supuso un desplazamiento político

29. Este argumento es mayoritariamente femenino. Las inmigrantes se quejan del liberalismo sexual de la región, especialmente de la visibilidad de los homosexuales y del comportamiento «ordinario» de las mujeres que «fuman, beben y hablan como los hombres». 
de distinto grado (dependiendo de las posiciones políticas familiares) hacia posiciones socialdemócratas.

\section{Estructura del habitus político}

Como advertimos anteriormente, con el objetivo de simplificar el análisis, los habitus políticos re-construidos son parciales o unidimensionales, es decir, solo dan cuenta de las disposiciones políticas generadas por una determinada condición de existencia o experiencia de vida. Respecto a la dimensión objetiva o determinante del habitus político, nos ha sorprendido que el campo social, el género y la generación no hayan resultado más importantes para la configuración de las disposiciones políticas, tal y como supusimos en nuestro diseño muestral ${ }^{30}$. La consecuencia de esto es que no hemos podido reconstruir habitus políticos a partir de estos criterios. Sin embargo, durante el análisis, pudimos identificar con claridad que $a$ ) el posicionamiento político familiar, $b$ ) la clase social (de origen y de destino), $c$ ) la trayectoria social y d) la trayectoria espacial actuaron como potentes estructuradores de la subjetividad política.

En cuanto a la dimensión subjetiva o determinada del habitus político, identificamos hasta ocho disposiciones políticas que fueron configuradas por las anteriores experiencias de vida. Estas son definidas a continuación.

La identificación política: hace referencia a la autoubicación del agente en el campo político mediante el continuo «derecha-centro-izquierda» o mediante el binomio "pinochetista/allendista». Es determinada, fundamentalmente, por el posicionamiento familiar en el conflicto histórico y, para los casos de identificación con la izquierda, también por la socialización política secundaria en la universidad, los partidos o los sindicatos.

La disposición discursiva: señala la predisposición del agente a reproducir un determinado tipo de discursos sobre el orden social, que pueden ser críticos, adaptativos o regresivos respecto a este ${ }^{31}$. Esta predisposición está configurada principalmente por el posicionamiento familiar en el conflicto histórico y por la clase social, siendo más relevante la clase de origen (de los padres) que la clase de destino (actual).

La preocupación social: se refiere a la disposición del agente a percibir y valorar determinados problemas sociales. Observamos que la capacidad para advertir distintos problemas sociales, así como el malestar que generan los

30. Aunque hay que recordar aquí que, por razones teóricas, el diseño muestral excluyó a la población desempleada e inactiva. Esto podría haber condicionado la relevancia de algunas propiedades sociales (como el género y la generación) para la configuración de los habitus políticos.

31. El universo discursivo identificado es demasiado extenso para poder dar aquí cuenta de él. Emergieron diez campos discursivos asociados al orden social, cada uno con sus diferentes posiciones discursivas. Los campos discursivos identificados hacían referencia al conflicto histórico, Chile, los chilenos, los inmigrantes, la minería, los sindicatos, las protestas sociales, la atribución de la posición social, la política y el modelo territorial (ver Rodrigo, 2013). 
mismos, está determinada esencialmente por el posicionamiento familiar en el conflicto histórico y por la clase social (de origen y actual).

La autovaloración: hace referencia a la disposición del agente a atribuirse un determinado grado de aprecio y, como consecuencia de este, el nivel de seguridad subjetiva con el que afronta las relaciones sociales. Por lo anterior, esta disposición está fuertemente asociada a la posición que adoptan los agentes ante las relaciones de dominación. Además, la autovaloración de los agentes también determina sus expectativas sociales. Agentes con una autovaloración baja y bajas expectativas sociales tienen mayor facilidad de adaptación al orden social neoliberal. En este sentido, consideramos que esta disposición es claramente política. La autovaloración y la seguridad de los agentes está fuertemente determinada por su clase social actual y, en menor medida, por su clase de origen.

La autonomía subjetiva: señala la disposición del agente hacia la independencia o hacia la dependencia social. La biografía de algunos agentes muestra una búsqueda sistemática de independencia socioeconómica motivada por un deseo de autonomía. Frente a estos, aparece también un patrón a establecer relaciones de dependencia mediante la búsqueda de figuras protectoras y proveedoras. Esta disposición se manifiesta en las relaciones que establece el agente con la familia, con la Administración pública, con la pareja y con el mercado laboral. Las relaciones sociales de dependencia (objetiva y/o subjetiva) dificultan o imposibilitan que los agentes puedan tomar posiciones críticas ante las relaciones de dominación y, en general, frente al orden social. Es este sentido, se consideran una disposición abiertamente política. La autonomía subjetiva aparece determinada principalmente por la clase social de origen.

La posición ante la dominación: se refiere a la disposición del agente a percibir y afrontar las relaciones de dominación. Esta disposición también es estructurada, fundamentalmente, por la clase social de origen. Observamos que los agentes socializados en las clases superiores y en el proletariado tienden a no percibir las relaciones de dominación en las que están involucrados, por estar estas naturalizadas. Frente a ellos, los agentes procedentes de la clase media, de la clase obrera-minera, así como los que han sufrido descenso social, tienden a percibir y a enfrentar, de distinta forma y dependiendo de sus recursos, las relaciones de dominación en las que están involucrados.

El sentimiento social: señala la disposición del agente al optimismo o al pesimismo social. En palabras de Bourdieu, a orientarse hacia el pasado (nostalgia) o hacia el futuro (ilusión). Esta disposición está configurada fundamentalmente por la trayectoria social de los agentes. Sus efectos son más nítidos cuanto mayor es la pendiente (ascendiente o descendiente) de dicha trayectoria. En las trayectorias ascendientes, observamos una tendencia al optimismo social, mientras que, en las descendientes, se observa una disposición al pesimismo y a la nostalgia. Los agentes con un sentimiento social negativo (pesimismo, nostalgia, frustración, etc.) son más proclives a adoptar posiciones regresivas o críticas frente al orden social. Por otro lado, los agentes con un sentimiento social positivo tienden a adoptar posiciones adaptativas con el orden social. Es, por ello, una disposición manifiestamente política. 
Cuadro 7. Relaciones entre las experiencias de vida y las disposiciones políticas

\begin{tabular}{lcccc}
\hline & \multicolumn{4}{c}{ Objetividad: experiencias de vida } \\
\cline { 2 - 5 } Subjetividad: & $\begin{array}{c}\text { Posicionamiento } \\
\text { disposítico familiar }\end{array}$ & Clase social & $\begin{array}{c}\text { Trayectoria } \\
\text { social }\end{array}$ & $\begin{array}{c}\text { Trayectoria } \\
\text { espacial }\end{array}$ \\
\hline Identificación políticas & $\mathrm{X}$ & $\mathrm{X}$ & & \\
Disposición discursiva & $\mathrm{X}$ & $\mathrm{X}$ & & \\
Preocupación social & & $\mathrm{X}$ & & \\
Autovaloración & & $\mathrm{X}$ & & \\
Autonomía subjetiva & & $\mathrm{X}$ & & \\
Posición ante la dominación & & & $\mathrm{X}$ & $\mathrm{X}$ \\
Sentimiento social & & & & \\
Valoración territorial & & & & \\
\hline
\end{tabular}

La valoración territorial: hace referencia a la disposición del agente para evaluar y apreciar Chile y la región de Antofagasta. Esta disposición aparece determinada principalmente por la trayectoria espacial del agente, esto es, por la experiencia de haber vivido en otro territorio (país o región de Chile). En general, la experiencia de haber vivido en un modelo socioeconómico distinto al neoliberal y/o culturalmente menos conservador predispone a realizar una valoración crítica de la sociedad chilena. Sin embargo, las experiencias de vida en países neoliberales y conservadores (Perú) o en otras regiones de Chile producen valoraciones ambivalentes ${ }^{32}$.

\section{Conclusiones}

Después de lo expuesto, resulta evidente, sin cuestionar la relevancia de los discursos políticos $^{33}$, que la relación con el orden social es prediscursiva o preconsciente (Bourdieu, 2008: 30-31), es decir, que no está causada (únicamente) por la posición discursiva, aunque esta produzca efectos posteriores. Esta constatación muestra la necesidad de ir más allá del análisis de los discursos (estructuras de subjetividad social) y reafirma la importancia del habitus (estructuras de subjetividad individual) como una herramienta teórico-metodológica adecuada para la comprensión del problema político.

Sabemos que el posicionamiento en el conflicto histórico determina en gran medida el posicionamiento en el resto del universo político; por ejemplo: quien mantenga una posición allendista estará más próximo al discurso del doble expolio, mientras que quien mantenga una posición pinochetista estará más próximo al discurso nacionalista y al meritocrático. Ahora bien, comprobar

32. Estas valoraciones fueron desarrollas en la presentación de los habitus políticos determinados por la trayectoria espacial.

33. Está demostrado que reproducir un discurso conservador aumenta la justificación al orden social (Levin et al., 1998; Jost y Thompson, 2000; Carbacho y Haye, 2008; Haye et al., 2009). 
que existe una cierta coherencia y consistencia entre las posiciones que asumen los agentes en los distintos campos del universo político no puede hacernos olvidar dos hechos esenciales: en primer lugar, dicha coherencia discursiva siempre es parcial y es el resultado del esfuerzo permanente que realizan los agentes por dotar a su relato de consistencia. Resulta, de hecho, muy frecuente encontrar fuertes contradicciones político-lógicas entre las posiciones discursivas de los agentes que pueden ser sociológicamente explicadas por sus trayectorias de vida. En segundo lugar, tampoco podemos desconocer que el posicionamiento discursivo de los agentes, pese a su relevancia, no agota ni comprende toda su relación con el orden social. En este sentido, el análisis realizado nos muestra como, por ejemplo, los agentes originarios de la misma clase social comparten propiedades subjetivas tan importantes para su relación con el orden social como la autovaloración, las expectativas socioeconómicas o la respuesta a las relaciones de dominación, y esto ocurre aunque sus posicionamientos discursivos sean totalmente antagónicos. Estos elementos nos obligan a resituar la relación entre el discurso social y el orden social, y a ampliar (sin desplazar) el foco desde el análisis del discurso hasta el análisis de la adquisición de disposiciones políticas.

\section{Referencias bibliográficas}

Alonso, Luis Enrique (1998). La mirada cualitativa en sociologia: una aproximación interpretativa. Madrid: Editorial Fundamentos.

Althusser, Louis (1974). Ideología y aparatos ideológicos de Estado. Buenos Aires: Nueva Visión.

Aroca, Patricio y Atienza, Miguel (2008). «La conmutación regional en Chile y su impacto en la Región de Antofagasta». EURE [en línea], 102, 97-120. <http://dx.doi.org/10.4067/S0250-71612008000200006>

Arriagada, Arturo; Navia, Patricio y Schuster, Martín (2010). « ¿ Consumo luego pienso, o pienso y luego consumo?: Consumo de medios, predisposición política, percepción económica y aprobación presidencial en Chile» Revista de Ciencia Politica [en línea], 30(3), 669-695. <http://dx.doi.org/10.4067/S0718-090X2010000300005>.

Banco Central de Chile. Indicadores sectoriales [en línea]. Santiago de Chile. $<$ http://www.bcentral.cl/es/faces/estadisticas/CNacionales/PIBRegional> [Consulta: 15 diciembre 2015].

Bourdieu, Pierre (1988). Cosas dichas. Barcelona: Gedisa.

- (1991). El sentido práctico. Madrid: Taurus.

- (1998). La distinción: criterio y bases sociales del gusto. Madrid: Taurus.

- (2001). Poder, derecho y clases sociales. Bilbao: Desclée.

- (2002). Razones prácticas: Sobre la teoría de la acción. Barcelona: Anagrama.

- (2003a). Cuestiones de sociología. Madrid: Istmo.

- (2003b). La dominación masculina. Barcelona: Anagrama.

- (2008). ¿Qué significa hablar?: Economía de los intercambios lingüisticos. Madrid: Akal.

Bourdieu, Pierre y WaCquant, Loïc J.D. (2005). Una invitación a la sociología reflexiva. Buenos Aires: Siglo XXI. 
Bourgois, Philippe y Schonberg, Jeff (2008). «Apartheid íntimo: Dimensiones étnicas del habitus entre los heroinómanos sin techo». Pensar, 3-4.

Canales, Manuel (2006). «El grupo de discusión y el grupo focal». En: Canales, Manuel, Metodologías de Investigación Social, 265-288. Santiago: LOM.

Canales, Manuel (2007). «Ni pobres ni incluidos: ¿nueva cuestión social?». Revista de Sociología, 21, 193-207. <http://dx.doi.org/10.5354/0716-632x.2007.27523>.

Carvacho, Héctor y Haye, Andrés (2008). «Configuración ideológica y estructura social: Resucitando el problema desde la psicología política». Revista de Psicología: Universidad de Chile [en línea], 17(2), 81-94. <http://dx.doi.org/10.5354/0719-0581.2008.17138>.

Casen (2009). Ministerio de Desarrollo Social, Gobierno de Chile: <http://www. ministeriodesarrollosocial.gob.cl/basededatoscasen_2009.php >.

Colectivo IOÉ (2010). «PPara qué sirve el grupo de discusión?: Una revisión crítica del uso de técnicas grupales en los estudios sobre migraciones». Empiria [en línea], 19, 73-99. <http://dx.doi.org/10.5944/empiria.19.2010.2015>.

Comisión Chilena del Cobre. Bases de datos [en línea]. Santiago de Chile: Ministerio de Minería. <www.cochilco.cl/estadisticas/intro-bd.asp> [Consulta: 13 enero 2012].

Conde, Fernando (2009). Análisis sociológico del sistema de discursos. CIS (43). Madrid.

Connolly, Paul; Kelly, Berni y Smith, Alan (2009). "Ethnic habitus and young children: A case study of Northern Ireland». European Early Childhood Education Research Journal [en línea], 17(2), 217-232. <http://dx.doi.org/10.1080/13502930902951460>.

Criado, Enrique M. (2013). «Cabilia: la problemática génesis del concepto de habitus». Revista Mexicana de Sociología, 75(1), 125-151.

Ferreira, Miguel A.V. y Ferrante, Carolina (2010). «El habitus de la discapacidad: La experiencia corporal de la dominación en un contexto económico periférico». Politica y Sociedad, 47(1), 85-104.

Festinger, Leon (1975). Teoría de la disonancia cognoscitiva. Madrid: Instituto de Estudios Políticos.

Freud, Anna (1997). El yo y los mecanismos de defensa. Barcelona: Paidós.

Fromm, Erich (1973). El miedo a la libertad. Buenos Aires: Paidós.

García, Adolfo (2011). "Micro-conflictos espaciales y habitus político de los grupos contra-hegemónicos». Nómadas: Revista Crítica de Ciencias Sociales y Jurídicas [en línea], 31(3), 257-276. <http://dx.doi.org/10.5209/rev_NOMA.2011.v31.n3.36820>.

Haye, Andrés et al. (2009). «Relación entre orientación política y condición socioeconómica en la cultura política chilena: Una aproximación desde la psicología social». Polis, 8(23), 351-384.

IвÁÑez, Jesús (1979). Más allá de la sociología: El grupo de discusión: técnica y crítica. Madrid: Siglo XXI.

Informe Rettig [en línea]. Gobierno de Chile. Ministerio del Interior y Seguridad Pública, 1991. <http://www.ddhh.gov.cl/ddhh_rettig.html>.

Informe Valech [en línea], 2004. <http:/www.derechoshumanos.net/paises/America/ derechos-humanos-Chile/informes-comisiones/Informe-Comision-Valech.pdf> [Consulta: 2 diciembre 2015].

Jost, John T. y Thompson, Erik P. (2000). «Group-based dominance and opposition to equality as independent predictors of self-esteem, ethnocentrism, and social 
policy attitudes among African Americans and European Americans». Journal of Experimental Social Psychology [en línea], 36, 209-232. <http://dx.doi.org/10.1006/jesp.1999.1403>.

Jost, John T. y BANAJI, Mahzarin R. (1994). "The role of stereotyping in system-justification and the production of false consciousness». British Journal of Social Psychology [en línea], 33, 1-27. <http://dx.doi.org/10.1111/j.2044-8309.1994.tb01008.x>.

Jost, John T.; Banaji, Mahzarin R. y Nosek, Brian A. (2004). «A decade of system justification theory: Accumulated evidence of conscious and unconscious bolstering of the status quo». Political Psychology [en línea], 25(6), 881-919. <http://dx.doi.org/10.1111/j.1467-9221.2004.00402.x>.

LACLAU, Ernesto (2000). Nuevas reflexiones sobre la revolución de nuestro tiempo. Buenos Aires: Nueva Visión.

Laclau, Ernesto y Mouffe, Chantal (1987). Hegemonía y estrategia socialista: Hacia una radicalización de la democracia. Madrid: Siglo XXI.

Lagos, Marta (2007). «Chile: Una prosperidad no democrática.» Revista de Sociología, 21, 139-163. <http://dx.doi.org/10.5354/0716-632x.2007.27521>

LATiNOBAROMETro (2009). <http://www.latinobarometro.org/latContents.jsp>

"Informes anuales». Latinobarómetro: Opinión Pública Latinoamericana [en línea]. Santiago de Chile: Corporación Latinobarómetro, 2008. <http://www.latinoba rometro.org/latino/LATContenidos.jsp> [Consulta: 10 enero 2012].

Levin, Shana et al. (1998). "Ethnic identity, legitimizing ideologies, and social status: A matter of ideological asymmetry». Political Psychology [en línea], 19, 373-404.

<http://dx.doi.org/10.1111/0162-895X.00109>.

López, Miguel Ángel y Morales, Mauricio (2005). «La capacidad explicativa de los determinantes familiares en las preferencias electorales de los chilenos». Política [en línea], 45, 87-108. <http://dx.doi.org/10.5354/0716-1077.2005.26101>.

Lira, E y Castillo, M.I. (1993). "Trauma político y memoria social», Psicología Política, 6, 95-116.

Marcuse, Herbert (1993). El hombre unidimensional. Barcelona: Planeta.

Marx, Karl (2001). Manuscritos de economía y filosofía. Madrid: Alianza.

- (2005). El capital. Tomo III, El proceso de producción capitalista. Buenos Aires: Siglo XXI.

MarX, Karl y Engels, Friedrich (1994). La ideología alemana. Valencia: Universitat de València.

Mayol, Alberto (2012). El derrumbe del modelo: La crisis de la economía de mercado en el Chile contemporáneo. Santiago de Chile: LOM.

Moulian, Tomás (2002). Chile actual: Anatomía de un mito. Santiago de Chile: LOM.

OrTí, Alfonso (1989). «La apertura y el enfoque cualitativo o estructural: La entrevista abierta y la discusión de grupo». El análisis de la realidad social: Métodos y técnicas de investigación. Madrid: Alianza.

Pujadas, Juan J. (1992). El método biográfico: El uso de las historias de vida en ciencias sociales. Madrid: CIS.

Rodrigo, Luis Miguel (2013). Adaptación y resistencia al orden social neoliberal en Chile: habitus y discursos sociales El caso de la Región de Antofagasta [en línea]. Tesis doctoral. Universidad de Valencia. <http://roderic.uv.es/handle/10550/26360>. 
Rodrigo, Luis Miguel y Atienza, Miguel (2014). «Migración y representaciones regionales: Discursos sobre la Región de Antofagasta». EURE [en línea], 120, 159-181. <http://dx.doi.org/10.4067/S0250-71612014000200008>.

RodríGuEZ, José M. (2003). «La producción de la subjetividad en los tiempos del neoliberalismo: Hacia un imaginario con capacidad de transformación social». Cuadernos de Relaciones Laborales, 21(1), 89-105.

Salazar, Gabriel y Pinto, Julio (1999). Historia contemporánea de Chile I: Estado, legitimidad y ciudadanía. Santiago de Chile: LOM.

SÁNCHEZ, Raúl (2008). «Habitus y clase social en Bourdieu: Una aplicación empírica en el campo de los deportes de combate». Papers, 89, 103-125.

Sandoval, Juan y Hatibovic, Fuad (2010). «Socialización política y juventud: El caso de las trayectorias ciudadanas de los estudiantes universitarios de la Región de Valparaíso». Última Década [en línea], 32, 11-36. $<$ http://dx.doi.org/10.4067/S0718-22362010000100002>.

WaCQUANT, Loïc (2011). «Habitus as topic and tool: Reflections on becoming a prizefighter». Qualitative Research in Psychology [en línea], 8(1), 81-92. $<$ http://dx.doi.org/10.1080/14780887.2010.544176>.

Weber, Max (2008). Economía y sociedad. México, D.F.: Fondo de Cultura Económica.

ŽıžEK, Slavoj (2004). Ideología: Un mapa de la cuestión. Buenos Aires: Fondo de Cultura Económica de Argentina.

- (2010). El sublime objeto de la ideología. Madrid: Siglo XXI. 